\title{
A systematic review of the quality of studies on dementia prevalence in Italy
}

\author{
Gianluca Bruti ${ }^{1 \dagger}$, Elisabetta Cavallucci ${ }^{1 \dagger}$, Michele Mancini ${ }^{1{ }^{*}}$, Alessandro Bitossi ${ }^{1}$, Marzia Baldereschi ${ }^{2}$ \\ and Sandro Sorbi ${ }^{3}$
}

\begin{abstract}
Background: Dementia, including Alzheimer's disease (AD), is one of the most burdensome medical conditions. In order to better understand the epidemiology of dementia in Italy, we conducted a systematic search of studies published between 1980 and April 2014 investigating the prevalence of dementia and AD in Italy and then evaluated the quality of the selected studies.

Methods: A systematic search was performed using PubMed/Medline and Embase to identify Italian population-based studies on the prevalence of dementia among people aged $\geq 60$ years. The quality of the studies was scored according to Alzheimer's Disease International (ADI) criteria.

Results: Sixteen articles on the prevalence of dementia and AD in Italy were eligible and $75 \%$ of them were published before the year 2000. Only one study was a national survey, whereas most of the studies were locally based (Northern Italy and Tuscany). Overall, the 16 studies were attributed a mean ADI quality score of 7.6 (median 7.75).

Conclusions: Available studies on the prevalence of dementia and AD in Italy are generally old, of weak quality, and do not include all regions of Italy. The important limitations of the few eligible studies included in our analysis, mostly related to their heterogeneous design, make our systematic review difficult to interpret from an epidemiologic point of view. Full implementation of a Dementia National Plan is highly needed to better understand the epidemiology of the disease and monitor dementia patients.
\end{abstract}

Keywords: Alzheimer's disease, Dementia, Epidemiology, Italy

\section{Background}

\section{Rationale}

Dementia, including Alzheimer's disease (AD), is one of the most burdensome medical conditions. As the prevalence of dementia increases with age, the number of people living with this condition is expected to surge in the next few decades as people live longer.

What is known about the epidemiology of dementia in Italy comes from prevalence data which typically have been generated from studies that may be inconsistent regarding diagnostic criteria, age of the studied population, or assessments used [1-3]. While there are also many publications on the prevalence of dementia in Western

\footnotetext{
* Correspondence: mancini_michele@lilly.com

${ }^{\dagger}$ Equal contributors

${ }^{1}$ Eli Lilly Italia S.p.A, Via A. Gramsci 731/733, 5019 Sesto Fiorentino, Fl, Italy

Full list of author information is available at the end of the article
}

European countries, the results of these studies vary considerably [4]. There is therefore an urgent need to come to a methodological consensus on how best to design epidemiological studies of dementia [2].

One important determinant of a reliable evaluation is the quality of the studies examined. In general, the quality of prevalence studies of dementia to date reflects the difficulty of diagnosing dementia. It has been suggested that a dementia diagnosis should be based upon a multidomain cognitive test battery, an informant interview, and a structured disability assessment, as well as a clinical interview to eliminate other causes of cognitive impairment [4]. Following very restricted criteria, Prince and colleagues [4] selected and ranked 51 European studies according to the standardized scoring system described in the 2009 Alzheimer Disease International (ADI) report 
[5] (Appendix). In this very comprehensive work, the European studies yielded a good ( \pm standard deviation) mean quality score, with $8.2 \pm 1.8$ points (range of mean \pm standard deviation quality scores of the studies across all regions: $5 \pm 0.7$ to $9.7 \pm 2$; overall mean all-region quality score: $7.9 \pm 2$ ) although only $8 \%$ of the studies referred to post-2000 research. This suggests that data are lacking on the prevalence of dementia in Europe in the last decade [4]. Nevertheless, the authors confirmed the prevalence data reported by the European Collaboration for Dementia Group (EuroCoDe) [1], with an age and gender standardized prevalence of $7.3 \%$, which is very similar to the $7.1 \%$ prevalence previously estimated by the EuroCoDe group [1].

Another important systematic review was conducted on prevalence data of dementia in Europe by the Alzheimer Cooperative Valuation in Europe (ALCOVE) [6]. This systematic review took into consideration both the quality of the studies (according to the quality score proposed by the 2009 ADI report [5]; Appendix) and the use of standardized clinical criteria (e.g. Diagnostic and Statistical Manual of Mental Disorders, DSM) [5, 7]. According to these methods, only 3 of the 17 studies selected in the EuroCoDe review [1] and 10 of the 12 studies in the ALCOVE review [6] adopted the clinical criteria of the DSM-IV. The DSM-IV criteria were chosen as a benchmark by the authors because it was the most frequently used method in these epidemiological studies. The mean quality score of all studies that adopted the DSM-IV criteria was $6.85 \pm 1.93$ (median 7 , range 4.510.5 ), whilst in those with a quality score $\geq 7$ the authors found a prevalence of dementia of $7.2 \%$. The use of these stringent criteria led to a mean decrease of $22 \%$ in total rate for dementia, compared with the EuroCoDe review estimates [1], and to a mean decrease of $12 \%$ in the total rate of dementia, compared with ALCOVE review estimates [6].

\section{Objectives}

The objectives of this systematic review were: (i) to conduct a review of studies on prevalence of dementia in Italy; and (ii) to evaluate the quality of identified studies according to the standardized scoring system for the assessment of epidemiological trials in dementia.

\section{Methods}

We estimated the quality of studies conducted on the prevalence of dementia and AD in Italy by carrying out a systematic review of the Italian literature published between January 1st 1980 and April 1st 2014, using PubMed/Medline and Embase and searching for the following terms (in any field): (dementia OR Alzheimer disease OR Alzheimer's disease) AND prevalence AND
Italy, with no language restriction. We sought and included all Italian population-based studies on the prevalence of dementia among people with age equal to or greater than 60 years old. In order to get a comprehensive ranking of the quality of studies published to date on the prevalence of dementia and $\mathrm{AD}$ in Italy, we excluded only the following papers:

1) Studies of prevalence from the follow-up phase of a population cohort;

2) Studies of nursing home or residential care populations, primary care attendees, or other unrepresentative service-user populations;

3) Studies in which the ascertainment of dementia depended upon help-seeking and/or receipt of dementia care services;

4) Studies restricted to young-onset dementia:

5) Reviews, meta-analyses and pooled analyses were not considered but could only have been used to find the proper original studies.

Two authors read the abstracts of all publications identified on the electronic databases, excluding only those that clearly did not meet the aforementioned eligibility criteria. In the next stage, four authors read the full-text versions of the selected publications and a consensus was reached regarding those remaining studies which met all criteria. The process of article selection followed PRISMA guidelines [8] and is illustrated in Fig. 1.

For evaluating the quality of the studies, we adopted the same approach described in the review by Prince et al. [4]. The scoring system used to assess the quality of the studies (which considered sample size, design, response proportion and diagnostic assessment; range $0-11)$ is presented in Appendix. In order to quantify the studies that adopted the DSM-IV and the National Institute of Neurological and Communicative Disorders and Stroke and the Alzheimer's Disease and Related Disorders Association (NINCDS-ADRDA) criteria, the type of diagnostic tool and clinical criteria for the diagnosis of dementia were also considered [6]. When it was not clear how to classify the quality of some publications, the four authors came to a consensus following discussion. Zero points were assigned to items for which the scoring was not applicable due to lack of information. In order to globally evaluate the quality of the epidemiological data available regarding the prevalence of dementia and $\mathrm{AD}$ in Italy, we first scored each study and then calculated the mean, range of scores, standard deviation and median of the overall quality score.

\section{Results}

Our systematic search yielded titles for 977 publications in Medline and for 966 publications in Embase. After 


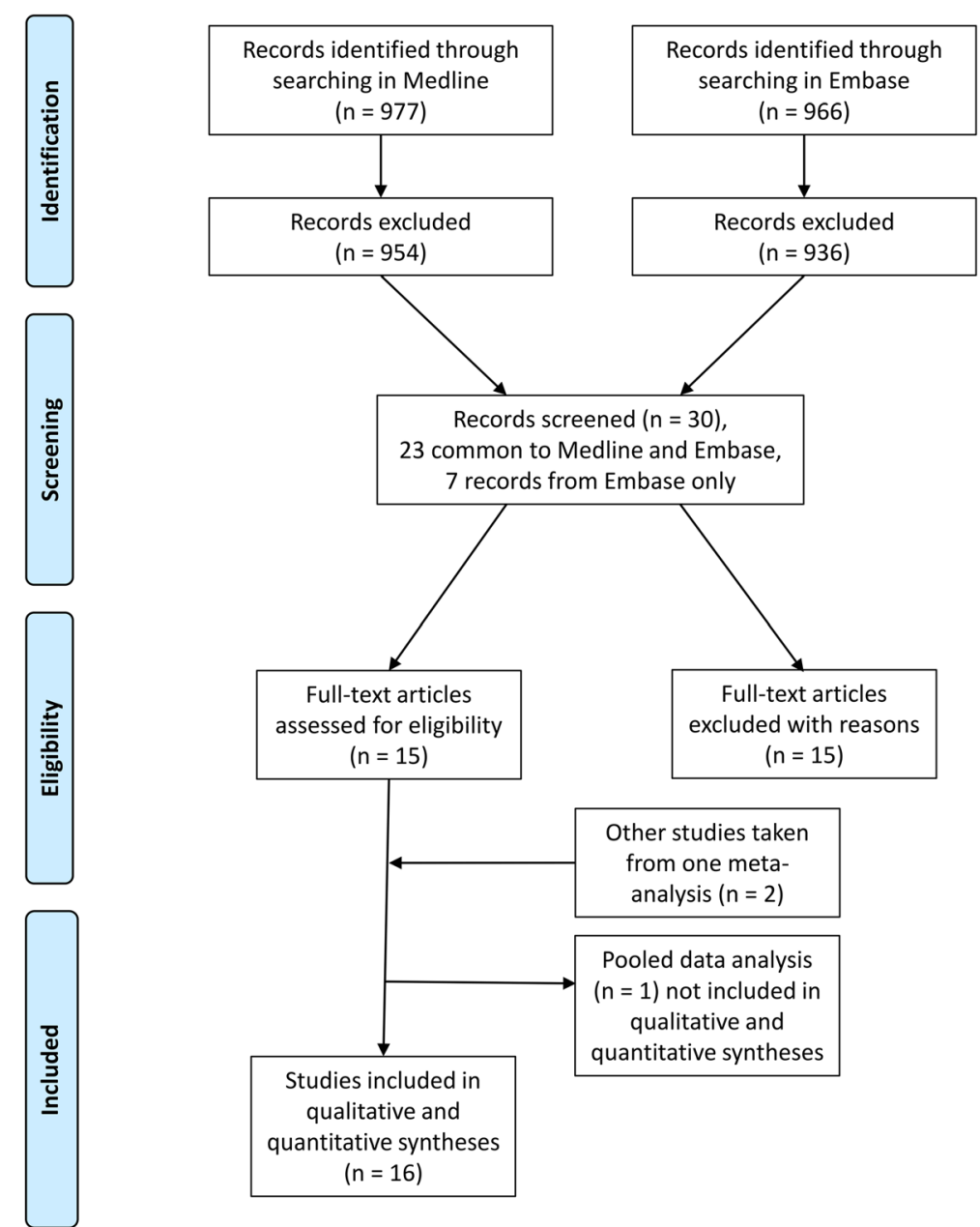

Fig. 1 Overview of article selection (PRISMA 2009)

reading the abstracts, 954 publications from Medline and 936 from Embase were excluded as clearly ineligible, leaving 30 articles for further review. Of these 30 articles, 23 were common to both libraries and seven were retrieved from Embase only. After obtaining copies of the fully published versions of each study, 15 publications were excluded (including all seven additional references from Embase) because they were deemed ineligible or were duplicates of publications already included.

We therefore analyzed 15 publications [9-23], comprising 14 different single studies and a pooled data analysis of 4 studies [23]. Two out of the four studies $[10,18]$ considered in the pooled data analysis [23] were already included in the list of the 14 single studies. Further to this, two other studies $[24,25]$ mentioned in the pooled analysis were also added into our analysis. These two studies did not focus on the prevalence of dementia and were not identified using the keywords used for our literature search; however, they did report data of interest. For these last two studies we integrated the data of interest obtained from the pooled analysis in Francesconi et al. [23] with those in the original publications. In this way, 16 of the 17 retrieved studies, i.e. all studies except the pooled data analysis [23], were included for the final analysis of the quality score (Fig. 1). Features of each study together with their quality score are outlined in Table 1 . Finally, as shown in Table 2, only the studies included in the most comprehensive and frequently cited European publications on the prevalence of dementia in Europe were considered suitable for the quality analysis $[1,4,6,26,27]$. Out of 16 selected studies, $75 \%$ (12 of 16) were published before the year 2000 . The mean gap between the year of survey and year of publication was $4.1 \pm 1.9$ years (median, 4 years).

Apart from the Italian Longitudinal Study on Aging (ILSA) survey [10], most of the studies evaluated the 
Table 1 Characteristics, scoring and prevalence of dementia/AD in studies carried out in Italy

\begin{tabular}{|c|c|c|c|c|c|c|c|c|c|c|c|}
\hline $\begin{array}{l}\text { First author and } \\
\text { year of publication }\end{array}$ & $\begin{array}{l}\text { Year of } \\
\text { survey }\end{array}$ & Area of investigation & $\begin{array}{l}\text { Type of } \\
\text { dementia(s) }\end{array}$ & Age (years) & $\begin{array}{l}\text { Sample size } \\
\text { Score }\end{array}$ & $\begin{array}{l}\text { Design } \\
\text { Score }\end{array}$ & $\begin{array}{l}\text { Response } \\
\text { Proportion } \\
\text { Score }\end{array}$ & $\begin{array}{l}\text { Diagnostic assessment } \\
\text { Score }\end{array}$ & $\begin{array}{l}\text { Total } \\
\text { score }\end{array}$ & $\begin{array}{l}\text { Prevalence of } \\
\text { dementia }\end{array}$ & $\begin{array}{l}\text { Diagnostic criteria } \\
\text { tools }\end{array}$ \\
\hline Rocca, 1990 [9] & 1987 & Appignano (Macerata) & $\begin{array}{l}\mathrm{D}(\mathrm{AD}+ \\
\mathrm{MID}+\mathrm{MD})\end{array}$ & $>59$ & $\begin{array}{l}778 \\
\text { Score: } 1\end{array}$ & $\begin{array}{l}\text { Two-phase design } \\
\text { with negative screen } \\
\text { Score: } 1\end{array}$ & $\begin{array}{l}96 \% \\
\text { Score: } 3\end{array}$ & $\begin{array}{l}\text { AMT + MMSE + Blessed- } \\
\text { Roth + CE + IN } \\
\text { Score: } 3\end{array}$ & 8 & $\begin{array}{l}6.2 \% \\
(2.6 \% \mathrm{AD})\end{array}$ & $\begin{array}{l}\text { NINCDS-ADRDA } \\
\text { HIS }\end{array}$ \\
\hline \multirow[t]{3}{*}{ ILSA, 1997 [10] } & \multirow{3}{*}{$\begin{array}{l}1992- \\
1993\end{array}$} & \multirow[t]{3}{*}{8 municipalities } & \multirow[t]{3}{*}{ Any type } & \multirow[t]{3}{*}{$65-84$} & \multirow{3}{*}{$\begin{array}{l}5632 / 5462 \\
\text { (total/eligible) } \\
\text { Score: } 2\end{array}$} & \multirow{3}{*}{$\begin{array}{l}\text { Two-phase design } \\
\text { with negative screen } \\
\text { Score: } 1\end{array}$} & \multirow{3}{*}{$\begin{array}{l}84-64 \%^{a} \\
\text { Score: } 3\end{array}$} & \multirow{3}{*}{$\begin{array}{l}\text { IN + CE (MMSE/ADL/IADL) } \\
\text { Score: } 3\end{array}$} & \multirow[t]{3}{*}{9} & $7.2 \% \mathrm{~F}$ & DSM-III-R \\
\hline & & & & & & & & & & \multirow[t]{2}{*}{$5.3 \% \mathrm{M}$} & NINCDS-ADRDA \\
\hline & & & & & & & & & & & ICD-10 \\
\hline \multirow[t]{3}{*}{ Prencipe, 1996 [1 1] } & \multirow{3}{*}{$\begin{array}{l}1992- \\
1993\end{array}$} & \multirow[t]{3}{*}{ Aquila Province } & \multirow{3}{*}{$\begin{array}{l}\mathrm{D}(\mathrm{AD}+\mathrm{VaD}+ \\
\mathrm{ODD})\end{array}$} & \multirow[t]{3}{*}{$>64$} & \multirow{3}{*}{$\begin{array}{l}1147 \\
\text { Score: } 1\end{array}$} & \multirow{3}{*}{$\begin{array}{l}\text { Two-phase design } \\
\text { with negative screen } \\
\text { Score: } 1\end{array}$} & \multirow{3}{*}{$\begin{array}{l}84.4 \% \\
\text { Score: } 3\end{array}$} & \multirow{3}{*}{$\begin{array}{l}\text { MMSE/MSQ }+ \text { CE }+ \text { IN + } \\
\text { disability assessment } \\
\text { Score: } 4\end{array}$} & \multirow[t]{3}{*}{9} & \multirow{3}{*}{$\begin{array}{l}8.0 \% \\
(5.2 \% \mathrm{AD})\end{array}$} & NINCDS-ADRDA \\
\hline & & & & & & & & & & & NINDS-AIREN \\
\hline & & & & & & & & & & & HIS \\
\hline $\begin{array}{l}\text { De Ronchi, } 1998 \\
\text { [12] }\end{array}$ & 1991 & Granarolo (Ravenna) & $\begin{array}{l}\mathrm{AD}+\mathrm{VaD}+ \\
\mathrm{MD}\end{array}$ & $\geq 61$ & $\begin{array}{l}557(481 \\
\text { completers) } \\
\text { Score: } 1\end{array}$ & $\begin{array}{l}\text { Two-phase design } \\
\text { with no negative } \\
\text { Score: } 0\end{array}$ & $\begin{array}{l}86.4 \% \\
\text { Score: } 3\end{array}$ & $\begin{array}{l}\text { MMSE/GDS + CE + } \\
\text { IN + ADL } \\
\text { Score: } 2\end{array}$ & 6 & $11.1 \%$ & DSM III R \\
\hline \multirow{3}{*}{$\begin{array}{l}\text { Benedetti, } 2002 \\
\text { [13] }\end{array}$} & \multirow[t]{3}{*}{1996} & \multirow[t]{3}{*}{ Buttapietra (Verona) } & \multirow[t]{3}{*}{$A D+V a D$} & \multirow[t]{3}{*}{$>74$} & \multirow{3}{*}{$\begin{array}{l}238 \\
\text { Score: } 0.5\end{array}$} & \multirow{3}{*}{$\begin{array}{l}\text { One-phase design } \\
\text { Score: } 2\end{array}$} & \multirow{3}{*}{$\begin{array}{l}93.3 \% \\
\text { Score: } 3\end{array}$} & \multirow{3}{*}{$\begin{array}{l}\text { MMSE + CE + IN + ADL } \\
\text { Score: } 3\end{array}$} & 8.5 & $15.8 \%$ & HIS \\
\hline & & & & & & & & & & $(6.7 \%$ AD) & NINCDS-ADRDA \\
\hline & & & & & & & & & & & DSM-III-R \\
\hline Ferini-Strambi, 1997 & 1991 & Vescovato (Cremona) & $\mathrm{AD}+\mathrm{VaD}+$ & $>59$ & $856(673$ & Two-phase design & $79 \%$ & $\mathrm{AMT}+\mathrm{CE}$ & 5 & $9.8 \%$ & NINCDS-ADRDA \\
\hline & & & $M D+S e D$ & & $\begin{array}{l}\text { responders) } \\
\text { Score: } 1\end{array}$ & $\begin{array}{l}\text { with no negative } \\
\text { Score: } 0\end{array}$ & Score: 2 & Score: 2 & & (5.2 \% AD) & NINDS-AIREN \\
\hline D'Alessandro, & 1992 & Troina (Enna) & $\mathrm{D}(\mathrm{VaD})$ & $>74$ & 365 & Two-phase design & $95 \%$ & $\mathrm{MMSE}+\mathrm{CE}+\mathrm{CDR}$ & 7.5 & $21.9 \%$ & DSM-III-R \\
\hline & & & & & & $\begin{array}{l}\text { with negative screen } \\
\text { Score: } 1\end{array}$ & Score: 3 & Score: 3 & & & HIS \\
\hline $\begin{array}{l}\text { Azzimondi, } 1998 \\
\text { [16] }\end{array}$ & $\begin{array}{l}1992- \\
1994\end{array}$ & $\begin{array}{l}2 \text { Sicilian Communities } \\
\text { (data on S. Agata } \\
\text { Militello) }\end{array}$ & $\mathrm{D}(\mathrm{VaD})$ & $>74$ & $\begin{array}{l}408 \\
\text { Score: } 1\end{array}$ & $\begin{array}{l}\text { Two-phase design } \\
\text { with negative screen } \\
\text { Score: } 1\end{array}$ & $\begin{array}{l}93 \% \\
\text { Score: } 3\end{array}$ & $\begin{array}{l}\text { MMSE + CE + CDR } \\
\text { Score: } 3\end{array}$ & 8 & $28.4 \%$ & DSM-III-RHIS \\
\hline Cristina, 2001 [17] & $\begin{array}{l}1992- \\
1993\end{array}$ & Pavia Province & $\mathrm{D}$ & $\begin{array}{l}>65(40 \% \\
65-69 \text { and } \\
\text { all }>70)\end{array}$ & $\begin{array}{l}2442 \\
\text { Score: } 1.5\end{array}$ & $\begin{array}{l}\text { Two-phase design with } \\
\text { negative sample } \\
\text { Score: } 1\end{array}$ & $\begin{array}{l}68 \% \\
\text { Score: } 2\end{array}$ & $\begin{array}{l}\text { MMSE + IN + CE } \\
\text { Score: } 3\end{array}$ & 7.5 & $11.8 \%$ & DSM-III-R \\
\hline Tognoni, 2005 [18] & 2000 & Pisa Province & $\mathrm{VaD}+\mathrm{AD}+$ & $>65$ & 2366 & Two-phase design with & $68 \%$ & MMSE/CDR/CAMDEX + & 7.5 & $6.2 \%$ & NINCDS-ADRDA \\
\hline & & & & & & $\begin{array}{l}\text { Indirect sample of } \\
\text { negative screen }\end{array}$ & & Score: 3 & & & HIS \\
\hline & & & & & & & & & & & LBD \\
\hline & & & & & & & & & & & $\begin{array}{l}\text { MCADRC } \\
\text { DSM-IV }\end{array}$ \\
\hline Lucca, 2011 [19] & $\begin{array}{l}2002- \\
2010\end{array}$ & Monzino (Varese) & $D(A D)$ & $\begin{array}{l}\geq 80(80- \\
100)\end{array}$ & $\begin{array}{l}2316 \\
\text { Score: } 1.5\end{array}$ & $\begin{array}{l}\text { One-phase design } \\
\text { Score: } 2\end{array}$ & $\begin{array}{l}88 \% \\
\text { Registered } \\
\text { Score: } 3\end{array}$ & $\begin{array}{l}\text { MMSE/BIMC/CDR + CE + } \\
\text { IN + disability assessment } \\
\text { Score: } 4\end{array}$ & 10.5 & $32 \%$ & DSM-IV \\
\hline Ravaglia, 1999 [20] & 1994- & Bologna + Ravenna & $A D+V a D$ & $\geq 100$ & 154 & One-phase design & $65 \%$ & $\mathrm{MMSE}+\mathrm{CE}+\mathrm{IN}+$ & 7.5 & $61.9 \%$ & DSM-IV \\
\hline & & & & & & & 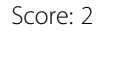 & $\begin{array}{l}\text { disability assessment } \\
\text { Score: } 3\end{array}$ & & D) & NINCDS-ADRDA \\
\hline
\end{tabular}


Table 1 Characteristics, scoring and prevalence of dementia/AD in studies carried out in Italy (Continued)

\begin{tabular}{|c|c|c|c|c|c|c|c|c|c|c|c|}
\hline Spada, 2009 [21] & $\begin{array}{l}2005- \\
2006\end{array}$ & San Teodoro (Enna) & $\begin{array}{l}A D+V a D+ \\
\text { Others }\end{array}$ & $60-85$ & $\begin{array}{l}374 \\
\text { Score: } 0.5\end{array}$ & $\begin{array}{l}\text { Two-phase design with } \\
\text { no negative screen } \\
\text { sample } \\
\text { Score: } 0\end{array}$ & $\begin{array}{l}74.9 \% \\
\text { Score: } 2\end{array}$ & $\begin{array}{l}\text { MMSE }+\mathrm{CE}+\mathrm{IN}+ \\
\text { disability assessment } \\
\text { Score: } 3\end{array}$ & 5.5 & $\begin{array}{l}7.1 \% \\
(4.1 \% \mathrm{AD})\end{array}$ & $\begin{array}{l}\text { DSM IV } \\
\text { NINCDS-ADRDA } \\
\text { NINDS-AIREN }\end{array}$ \\
\hline Ravaglia, 2002 [22] & $\begin{array}{l}1999- \\
2000\end{array}$ & Conselice (Ravenna) & $A D+V a D$ & $65-97$ & 1353 Score: 1 & $\begin{array}{l}\text { Two-phase design } \\
\text { with negative screen } \\
\text { sample } \\
\text { Score: } 1\end{array}$ & $\begin{array}{l}75 \% \\
\text { Score: } 2\end{array}$ & $\begin{array}{l}\text { MMSE }+C E+I N+ \\
\text { disability assessment } \\
\text { Score: } 3\end{array}$ & 7 & $\begin{array}{l}5.9 \% \\
(3.0 \% \mathrm{AD})\end{array}$ & $\begin{array}{l}\text { DSM-IV } \\
\text { NINCDS-ADRDA } \\
\text { NINDS-AIREN }\end{array}$ \\
\hline Ferrucci, 2000 [24] & 1998 & $\begin{array}{l}\text { Greve in Chianti + } \\
\text { Bagno a Ripoli } \\
\text { (Florence) }\end{array}$ & $D$ and $A D$ & $>65-90+$ & 1260 Score: 1 & $\begin{array}{l}\text { Two-phase design } \\
\text { with negative screen } \\
\text { Score: } 1\end{array}$ & $\begin{array}{l}91.6 \%{ }^{b} \\
\text { Score: } 3\end{array}$ & $\begin{array}{l}\text { MMSE }+C E+I N+ \\
\text { disability assessment } \\
\text { Score: } 3\end{array}$ & 8 & $\begin{array}{l}7.1 \% \\
(3.6 \% \mathrm{AD})^{\mathrm{d}}\end{array}$ & $\begin{array}{l}\text { DSM-III-R } \\
\text { NINCDS-ADRDA }\end{array}$ \\
\hline Di Bari, 1999 [25] & 1995 & Dicomano (Florence) & $D$ and $A D$ & $>65-90+$ & 864 Score: 1 & $\begin{array}{l}\text { Two-phase design } \\
\text { with negative screen } \\
\text { Score: } 0\end{array}$ & $\begin{array}{l}91.2 \%{ }^{b} \\
\text { Score: } 3\end{array}$ & $\begin{array}{l}\text { MMSE }^{c}+\text { MODA + } \\
\text { CE + BADL } \\
\text { Score: } 3\end{array}$ & 7 & $\begin{array}{l}9.0 \% \mathrm{z} \\
(5.2 \% \mathrm{AD})^{\mathrm{d}}\end{array}$ & Unknown \\
\hline
\end{tabular}

General: $F$ females, $M$ males, $N A$ not available

Type of dementia and other diseases: AD Alzheimer Disease, D Dementia, LBD Lewy Body Dementia, MCI Mild Cognitive Impairment, MD Mixed Dementia, MID Multi-Infarct Dementia, ODD Other Dementing Diseases, SeD Secondary Dementia, VaD Vascular Dementia

Area of investigation: SAM community of Sant'Agata Militello

Diagnostic assessment score: ADL Activities of Daily Living, AMT Abbreviated Mental Test, BADL Bristol Activities of Daily Living, BIMC Blessed Information Memory Concentration, CAMDEX Cambridge Mental Disorders of the Elderly Examination, CDR Clinical Dementia Rating, CE Clinical Examination, GDS Global Deterioration Scale, IADL Instrumental Activities of Daily Living, IN Interview, MDS Minimum Data Set, MMSE Mini-Mental State Examination, MODA Milan Overall Dementia Assessment, MSQ Mental Status Questionnaire

Diagnostic criteria tools: DSM Diagnostic and Statistical Manual of Mental Disorders, HIS Hachinski Ischemic Score, ICD International Classification of Diseases, MCARDC Mayo Clinic Alzheimer's Disease Research Center, NINCDS-ADRDA National Institute of Neurological and Communicative Disorders and Stroke-Alzheimer's Disease and Related Disorders Association, NINDS-AIREN National Institute of Neurological Disorders and Stroke-Association Internationale pour la Recherche et l'Enseignment en Neurosciences, RPM Raven Progressive Matrix

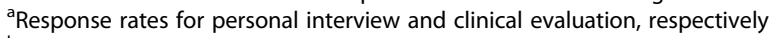

${ }^{\mathrm{b}}$ Calculated on those who were traceable

CMMSE and adjustment tests when score falls between 22 and 25

Estimated from Table 2 in the pooled analysis [23] 
Table 2 ADI quality score included in the meta-analysis on the prevalence of dementia in Europe (1980-2014)

\begin{tabular}{|c|c|c|c|c|}
\hline First author and/or name of survey & Range of time considered & Italian studies included & ADI quality score & $\begin{array}{l}\text { ADI quality score (mean } \pm S D ; \\
\text { median) (mean } \pm S D ; \text { median) }\end{array}$ \\
\hline Hofman, 1991, EURODEM [26] & 1980-1990 & Rocca et al., 1990 [9] & 8 & 8 \\
\hline Lobo, 2000, EURODEM [27] & 1990-2000 & ILSA, 1997 [10] & 9 & 9 \\
\hline \multirow[t]{5}{*}{ Reynish, 2006, EUROCODE [1] } & \multirow[t]{5}{*}{ 1990-2007 } & Prencipe et al., 1996 [11] & 9 & \multirow[t]{5}{*}{$7.3 \pm 1.5 ; 7.5$} \\
\hline & & Ferini-Strambi et al., 1997 [14] & 5 & \\
\hline & & Azzimondi et al., 1998 [16] & 8 & \\
\hline & & Ravaglia et al., 2002 [22] & 7 & \\
\hline & & Tognoni et al., 2005 [18] & 7.5 & \\
\hline Galeotti, 2013, ALCOVE [6] & $2007-2011$ & Lucca et al., 2011 [19] & 10.5 & 10.5 \\
\hline \multirow[t]{13}{*}{ Prince, 2013 [4] } & \multirow[t]{13}{*}{ 1980-2009 } & Rocca et al., 1990 [9] & 8 & \multirow[t]{13}{*}{$7.4 \pm 1.1 ; 7.5$} \\
\hline & & D’Alessandro et al., 1996 [15] & 7.5 & \\
\hline & & Prencipe et al., 1996 [11] & 9 & \\
\hline & & Ferini-Strambi et al., 1997 [14] & 5 & \\
\hline & & Azzimondi et al., 1998 [16] & 8 & \\
\hline & & De Ronchi et al., 1998 [12] & 6 & \\
\hline & & aDi Bari et al., 1999 [25] & 8 & \\
\hline & & Ravaglia et al., 1999 [20] & 7.5 & \\
\hline & & ${ }^{a}$ Ferrucci et al., 2000 [24] & 8 & \\
\hline & & Cristina et al., 2001 [17] & 6.5 & \\
\hline & & Ravaglia et al., 2002 [22] & 7 & \\
\hline & & Benedetti et al., 2002 [13] & 8.5 & \\
\hline & & Tognoni et al., 2005 [18] & 7.5 & \\
\hline
\end{tabular}

ADI Alzheimer Disease International, ALCOVE Alzheimer Cooperative Valuation in Europe, EuroCoDe European Collaboration for Dementia Group, ILSA Italian Longitudinal Study on Aging

${ }^{\mathrm{a}}$ For the calculation of the ADI quality score, the items reported in these publications have been integrated with those reported in the pooled data of Francesconi et al. [23]

prevalence of dementia in Northern Italy and Tuscany (10 of 16). Two studies were conducted in Central Italy $[9,11]$ and the remaining three studies were performed in Sicily [15, 16, 21] (Fig. 2). Even including the ILSA study, we did not find any data on the prevalence of dementia for 10 out of 20 Italian regions.

The prevalence of dementia in the Italian studies ranged from a minimum of $5.9 \%$ (for a sample with range of 65-97 years) to a maximum of $61.9 \%$ (for a sample with age $>100$ years) (Table 1). Out of the 16 studies included in this review, 13 reported prevalence by age and sex. Ten of 16 analyzed studies $(62.5 \%)$ reported the specific prevalence data for AD. We found in these 10 studies that the prevalence of AD increased with the age of the studied population (from $3 \%$ for a range of age of 65-97 years old to $48.9 \%$ for a study sample with age $>100$ years old) (Table 1). Only the ILSA study [10] had a sample size $>3000$ (Table 1). Twenty-five percent of the studies (4 of 16) considered 60 years to be the minimum age for inclusion (i.e. the conventional age threshold to define elderly), while the majority of studies used 65 years as the age threshold.

The majority of studies (62.5\%; 10 of 16) reported a response rate greater than or equal to $80 \%$. Regarding study design, only three studies (18\%) were performed with a one-phase design method $[13,19,20]$. Of the remaining studies, 13 had a two-phase design and 10 were conducted with sampling of screen negatives. No studies adopted the weighting back method (for all information see Table 1).

Table 1 also indicates the diagnostic tools used in the 16 studies. With regard to diagnostic assessment, the informant interview was performed in three of the 16 studies. A total of six studies adopted the NINCDS-ADRDA criteria, four studies adopted both the NINCDS-ADRDA and the DSM-IV criteria, and one study was performed with DSM-IV alone. The assessment tool used was not reported in one of the remaining five studies, whilst in four studies neither 


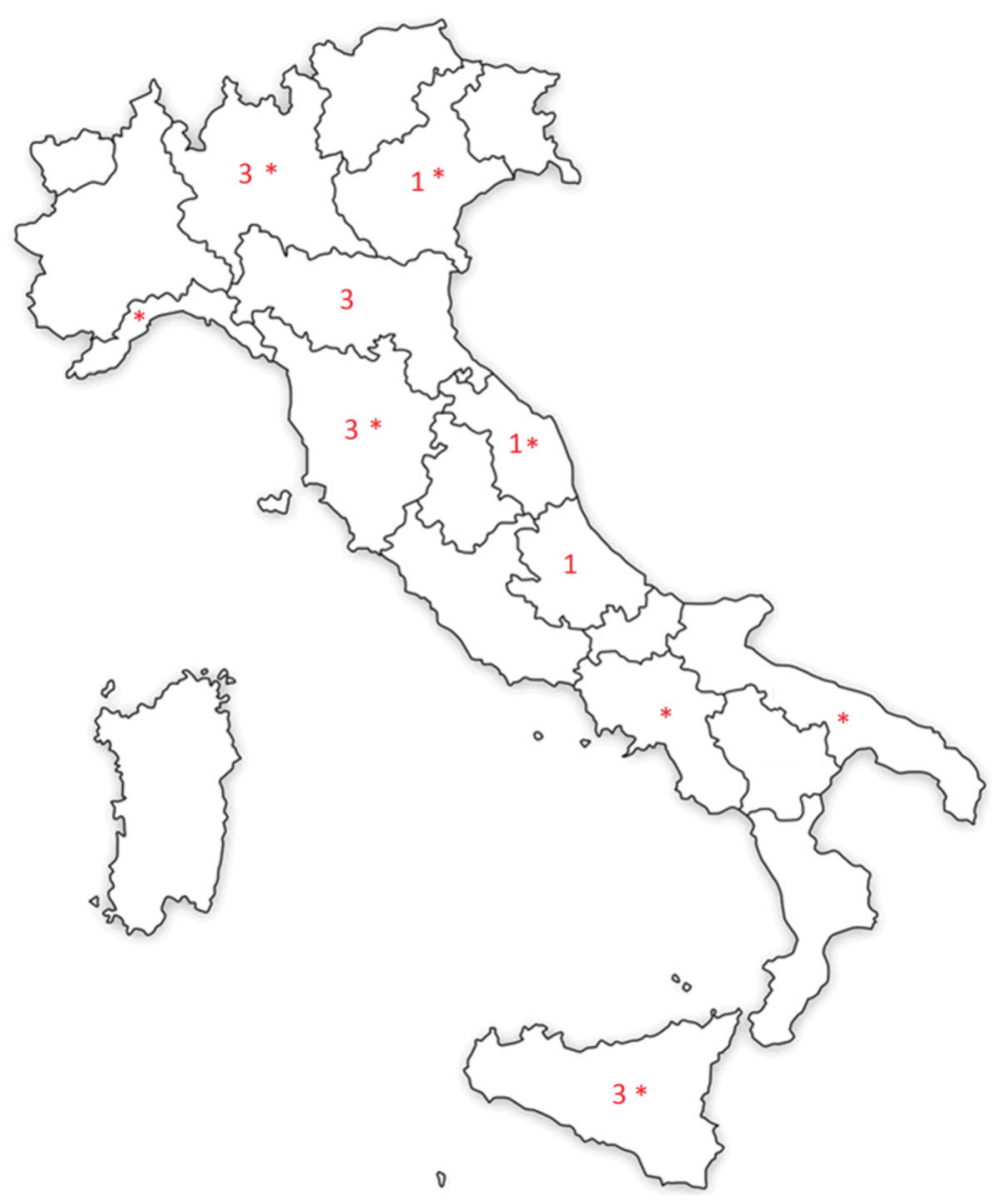

Fig. 2 Geographic distribution and the relative number of Italian publications on prevalence of dementia (map created by authors) Note: The asterisks refer to the municipalities included in the ILSA study [10]

the DSM-IV nor the NINCDS-ADRDA criteria were utilized. Overall, the 16 epidemiological studies scored a mean ADI quality score of $7.6 \pm 1.4$ with a median of 7.75. As shown in Fig. 3, there was only a slight tendency for study quality to improve over time.
When only the studies included in the Prince et al. [4] analysis were considered, the mean quality score of the Italian studies was found to be numerically less than that of the European studies $(7.4 \pm 1.1$ vs. $8.2 \pm$ 1.8) (Table 2).

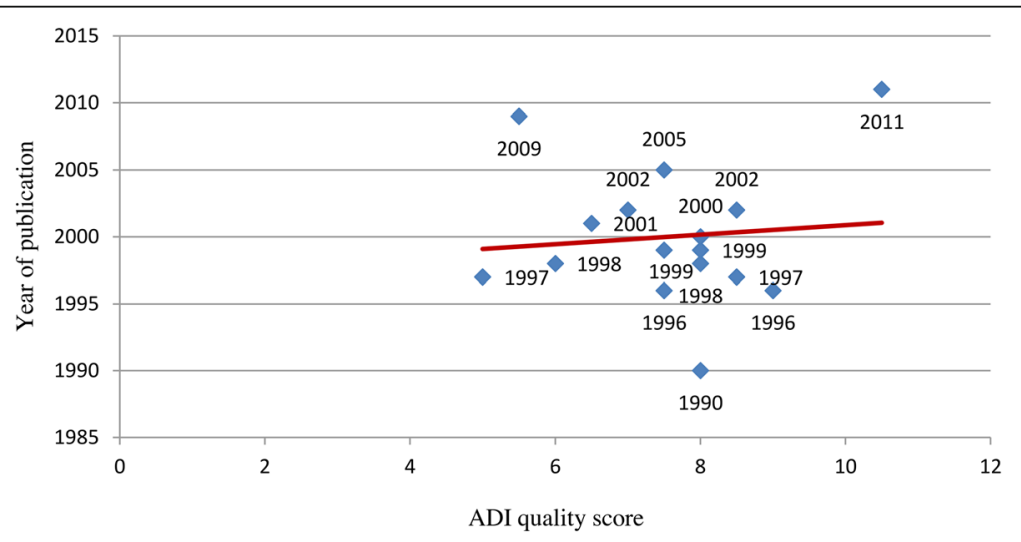

Fig. 3 Relationship between the quality of studies on the prevalence of dementia in Italy and the year of publication. ADI, Alzheimer Disease International 


\section{Discussion}

\section{Summary of evidence}

Overall, this systematic review showed that the analyzed studies do not represent a valid source of epidemiological data on the prevalence of dementia in Italy. We found that, until now, no epidemiological data for 10 out of 20 Italian regions were available and that the majority of epidemiological studies were performed at the level of municipalities, with most studies conducted in Northern Italy. Some regions were more affected by dementia than others.

Irrespective of geographical distribution, the prevalence rates of dementia reported in the Italian studies vary widely which may be due to important differences in methodological approaches and population age ranges. In the 16 studies analyzed, we found five different age ranges of study samples, a discrepancy that makes it difficult to compare the results of these studies and suggests a lack of methodological consensus. Furthermore, it is important to note that the only nationwide survey on the prevalence of dementia in Italy with a sample size $>3000$ subjects excluded those who were older than 84 years, an age range associated with a high rate of dementia.

From a diagnostic methodological perspective, the majority of Italian studies on the prevalence of dementia and $\mathrm{AD}$ included in our analysis adopted a two-phase design, but not all of them used sampling of screen negatives and none of them adopted the weighting back method. Furthermore, the informant interview was performed in only a minority of selected publications.

Overall, the Italian studies included in this review had lower ADI quality scores than those of European studies and, unlike the finding reported in the meta-analysis of Prince et al. [4], quality showed only a slight tendency to improve over time.

\section{Implications}

The finding of the lack of robust recent epidemiological data is in accordance with the global data reported in a meta-analysis, which showed that the number of epidemiological studies on the prevalence of dementia in high-income countries peaked in the 1990s and subsequently dropped off sharply [4]. Even if the prevalence of dementia and AD has not changed significantly over time [1], the paucity of epidemiological data on the prevalence of dementia in Italy over the last ten years is regrettable and has important implications from economic and social points of view. Indeed, annual updates of the actual number of patients with dementia residing in a country should be the first step in creating a policy supporting patients and their families. It is also noteworthy that the geographic distribution of territorial Alzheimer Evaluation Units in
Italy is not homogeneous, with the majority located in the north of the country [28]. This geographic distribution might explain, at least in part, why most epidemiological studies on dementia and AD in Italy have been performed in northern regions.

Another issue regarding studies on the prevalence of age-related diseases like dementia and $\mathrm{AD}$ is the timing of publication in relation to the time of survey. At a national level, health policy strategy is dependent on accurate and current estimates of the size of the problem $[1,4]$. The gap between the dates of the surveys and their dates of publication, together with the scarcity of recent data, suggests that the available publications on the prevalence of dementia in Italy may not represent an up-to-date source of information for health economic policy planning regarding patients with dementia.

Epidemiological studies on prevalence of dementia in Italy show low methodological quality. As Prince et al. [4] reported, multiphase methods in general tend to underestimate the prevalence of dementia and overestimate the precision. In accordance with other epidemiological studies [4], our analysis confirmed that many studies omitted the informant interview. Furthermore, prevalence estimates may reflect the diagnostic criteria adopted by each study. For example, a study that evaluated the prevalence of dementia using different systems of classification found that the proportion of subjects with dementia varied from $3 \%$ when International Classification of Diseases (ICD)-10 criteria were used to $29 \%$ when DSM-III criteria were applied [7]. Similarly, the variability observed in European epidemiological studies has been attributed precisely to the clinical criteria adopted $[1,6]$. In our analysis, $31 \%$ of the studies used neither the DSM-IV criteria nor the NINCDSADRDA criteria. This finding represents a major methodological issue considering that only the latter diagnostic criteria have been validated with post-mortem data [6].

The weak ADI quality scores of the Italian studies, along with evidence that quality showed only a slight tendency to improve over time, has important implications at the national healthcare system level. Since no national survey commissioned by the Italian government has been performed in Italy, we suggest that the Italian healthcare system should urgently institute nationally representative surveys using the highest quality epidemiological methods, as defined in the ADI 2009 report, and repeat them at regular intervals to track any changes in the prevalence of dementia or $\operatorname{AD}[4,6]$.

Based on the findings of our systematic review, we believe that the development of a national plan might be an appropriate strategy to obtain epidemiological estimates on dementia using the current healthcare system 
and, at the same time, we encourage researchers to undertake national surveys. A national plan might help overcome differences between Italian regions, whilst the detailed estimates obtained in this way might be useful for policymaking, planning, and allocation of health and welfare resources.

\section{Limitations}

This review has several limitations First, our selected studies included surveys that were not specifically dedicated to the prevalence of dementia $[10,24,25]$, which may have resulted in a bias in the types of publications included in the review. Second, although we reported that $75 \%$ of studies were published before the year 2000, this finding might be due to our search methodology as PubMed/Medline and Embase were the only databases searched. However, this bias is unlikely to be substantial since all studies included in our analysis (Table 2) were also included in the most relevant metaanalysis published in this field [4] Third, the quality of studies included in this review was low. Fourth, The mean gap of four years between the year of survey and the year of publication should also be taken into account. Fifth, the review was not listed on an international prospective register of systematic reviews such as PROSPERO [29]. Sixth, this review has the intrinsic methodological limitation that the prevalence rates derived from all the analyzed studies have not been standardized or compared with those of a reference population, e.g. one chosen for age and sex. Finally, it should also been taken into consideration that although the quality of the studies only slightly improved over time, our literature search for the studies on prevalence began in 1980 and $75 \%$ of the selected studies were published prior to 2000. Therefore, many of the included studies were unlikely to have been conducted in conformity with current requirements for epidemiological studies [30].

\section{Conclusions}

Despite the availability of several publications, data on the prevalence of dementia in Italy and their usefulness for evaluating the epidemiological burden of the disease in Italy are minimal. The majority of studies were conducted in the 1990s with important methodological and geographic differences that undermine determination of the true national prevalence of dementia. Overall, the quality of Italian studies was lower than that of European studies and only slightly improved over time. Full implementation of a Dementia National Plan would help physicians, scientists and regulators to better understand the epidemiology of dementia and $\mathrm{AD}$ in Italy.

\section{Appendix}

Standardized scoring system for the assessment of quality of epidemiological trials in dementia [5]

\begin{tabular}{ll}
\hline Item & Score \\
\hline Sample size & \\
$<500$ & 0.5 points \\
$500-1499$ & 1 point \\
$1500-2999$ & 1.5 points \\
$\geq 3000$ & 2 points \\
Design & \\
& \\
Two-phase study with no sampling of screen & 0 points \\
negatives & \\
Two-phase study with sampling of screen & 1 point \\
negatives but no weighting back & \\
One-phase study or two-phase study with & 2 points \\
appropriate sampling and weighting & \\
Response proportion & \\
$<60 \%$ & 2 point \\
$60-79 \%$ & 3 points \\
$\geq 80 \%$ & \\
Diagnostic assessment & 1 points \\
Inclusion of multidomain cognitive test battery, \\
formal disability assessment, informant interview \\
and clinical interview
\end{tabular}

${ }^{a}$ In the two-phase study, all participants are evaluated in the first phase using a screening tool. All the patients with a score below a predefined cutpoint (screen positives) will enter into the second phase of the study for a more comprehensive evaluation. In order to get a more correct evaluation, a random sample with a score above the cutpoint (screen negatives) should also be included in the second phase of the study. In this way the false positive rate can be estimated among the screen negatives and the related weight ('weight back') can be evaluated, calculating an overall prevalence taking into account the different sampling proportions of screen positives and screen negatives. In the one-phase study, all patients directly receive a comprehensive clinical evaluation

Abbreviations

AD: Alzheimer disease; ADI: Alzheimer Disease International; ALCOVE: Alzheimer Cooperative Valuation in Europe; DSM: Diagnostic and Statistical Manual of Mental Disorders; EuroCoDe: European Collaboration for Dementia Group; ICD: International Classification of Diseases; ILSA: Italian Longitudinal Study on Aging; NINCDS-ADRDA: National Institute of Neurological and Communicative Disorders and Stroke-Alzheimer's Disease and Related Disorders Association

\section{Acknowledgments}

The authors thank Elisa Solano (Eli Lilly and Company, Vienna, Austria) for administrative and editorial support and Dr Luca Cantini (Rx Communications Mold, UK) for linguistic and writing support, which was funded by Eli Lilly and Company.

Funding

Not applicable as this is a review article.

Availability of data and materials

Not applicable as this is a review article.

Authors' contributions

For the systematic review, $A B$ and EC read the abstracts of all publications identified on the electronic databases, excluding only those that clearly did 
not meet the aforementioned criteria. $A B, E C, M M$ and $G B$ read printed full-text copies of the remaining publications and a consensus was made on those studies which met all criteria. All authors read and approved the final manuscript.

\section{Competing interests}

Gianluca Bruti, Elisabetta Cavallucci, Michele Mancini, Alessandro Bitossi, are employees of Eli Lilly \& Company. Marzia Baldereschi has no conflicts of interest to declare. Sandro Sorbi is a member of the Lilly Alzheimer Europe and Lilly Italy advisory boards. He has been a speaker for Lilly and participates as a primary investigator in the LZAX (EXPEDITION 3) study.

\section{Consent for publish}

Not applicable as we do not present patient data.

\section{Ethics approval and consent to participate}

Not applicable as we do not present patient data.

\section{Author details}

'Eli Lilly Italia S.p.A, Via A. Gramsci 731/733, 5019 Sesto Fiorentino, FI, Italy. ${ }^{2}$ Institute of Neurosciences, Italian National Research Council, Via Madonna del Piano 10, 50019 Sesto Fiorentino, FI, Italy. ${ }^{3}$ Department of Neuroscience, Psychology, Drug Research and Child Health, University of Florence, Viale Pieraccini 6 Firenze and Centro IRCCS "Don Carlo Gnocchi", Via di Scandicci 269, Firenze, Italy.

\section{Received: 24 June 2015 Accepted: 11 August 2016}

\section{Published online: 26 October 2016}

\section{References}

1. Reynish E, Fratiglioni L, Prince M, Bickel H, Kiejna A, Georges J. Prevalence of Dementia in Europe. Alzheimer Europe. 2006. http://ec.europa.eu/health/ archive/ph_information/dissemination/diseases/docs/eurocode.pdf. Accessed 29 May 2015.

2. Misiak B, Cialkowska-Kuzminska M, Frydecka D, Chladzinska-Kiejna S, Kiejna A. European studies on the prevalence of dementia in the elderly: time for a step towards a methodological consensus. Int J Geriatr Psychiatry. 2013;28(12):1211-21.

3. Ravaglia G, Forti P. The Conselice study of brain ageing. Immun Ageing. 2010;7 Suppl 1:S2

4. Prince M, Bryce R, Albanese E, Wimo A, Ribeiro W, Ferri CR. The global prevalence of dementia: A systematic review and metaanalysis. Alzheimers Dement. 2013:9(1):63-75.

5. ADI/WAR. Alzheimer's Disease International. World Alzheimer Report 2009. London: Alzheimer's Disease International; 2009.

6. Galeotti F, Giusti A, Meduri F, Raschetti R, Scardetti P, Vanacore N. Epidemiological data on dementia. In: ALCOVE (Alzheimer cooperative valuation in Europe) synthesis report 2013. http://www.alcove-project.eu/ images/pdf/ALCOVE_SYNTHESIS_REPORT VF.pdf. Accessed 29 May 2015.

7. Erkinjuntti T, Østbye T, Steenhuis R, Hachinski V. The effect of different diagnostic criteria on the prevalence of dementia. N Engl J Med. 1997:337:1667-74.

8. Moher D, Liberati A, Tetzlaff J, Altman DG, PRISMA Group. Preferred reporting items for systematic reviews and meta-analyses: the PRISMA statement. PLoS Med. 2009;6(7):e1000097.

9. Rocca WA, Bonaiuto S, Lippi A, Luciani P, Turtù F, Cavarzeran F, et al. Prevalence of clinically diagnosed Alzheimer's disease and other dementing disorders: a door-to-door survey in Appignano, Macerata Province, Italy. Neurology. 1990:40(4):626-31.

10. ILSA. Prevalence of chronic diseases in older Italians: comparing selfreported and clinical diagnoses. The Italian Longitudinal Study on Aging Working Group. Int J Epidemiol. 1997:26(5):995-1002.

11. Prencipe M, Casini AR, Ferretti C, Lattanzio MT, Fiorelli M, Culasso F. Prevalence of dementia in an elderly rural population: effects of age, sex, and education. J Neurol Neurosurg Psychiatry. 1996;60(6):628-33.

12. De Ronchi D, Fratiglioni L, Rucci P, Paternicò A, Graziani S, Dalmonte E. The effect of education on dementia occurrence in an Italian population with middle to high socioeconomic status. Neurology. 1998;50(5):1231-8.

13. Benedetti MD, Salviati A, Filipponi S, Manfredi M, De Togni L, Gomez Lira M, et al. Prevalence of dementia and apolipoprotein e genotype distribution in the elderly of Buttapietra, Verona province, Italy. Neuroepidemiology. 2002:21(2):74-80.

14. Ferini-Strambi L, Marcone A, Garancini P, Danelon F, Zamboni M, Massussi P, et al. Dementing disorders in north Italy: prevallence study in Vescovato, Cremona Province. Eur J Epidemiol. 1997;13(2):201-4.

15. D'Alessandro R, Pandolfo G, Azzimondi G, Feruglio FS. Prevalence of dementia among elderly people in Troina, Sicily. Eur J Epidemiol. 1996;12(6):595-9.

16. Azzimondi G, D'Alessandro R, Pandolfo G, Feruglio FS. Comparative study of the prevalence of dementia in two Sicilian communities with different psychosocial backgrounds. Neuroepidemiology. 1998;17(4):199-209.

17. Cristina S, Nicolosi A, Hauser WA, Leite ML, Gerosa E, Nappi G. The prevalence of dementia and cognitive deficit in a rural population of 2442 residents in northern Italy. A door-to-door survey. Eur J Neurol. 2001;8(6):595-600.

18. Tognoni G, Ceravolo R, Nucciarone B, Bianchi F, Dell'Agnello G, Ghicopulos I, et al. From mild cognitive impairment to dementia: a prevalence study in a district of Tuscany, Italy. Acta Neurol Scand. 2005;112(2):65-71.

19. Lucca U, Garrì M, Recchia A, Logroscino G, Tiraboschi P, Franceschi M, et al. A population-based study of dementia in the oldest old: the Monzino 80-plus study. BMC Neurol. 2011;11:54.

20. Ravaglia G, Forti P, De Ronchi D, Maioli F, Nesi B, Cucinotta D, et al. Prevalence and severity of dementia among northern Italian centenarians. Neurology. 1999:53(2):416-8.

21. Spada RS, Stella G, Calabrese S, Bosco P, Anello G, Guéant-Rodriguez RM, et al. Prevalence of dementia in mountainous village of Sicily. J Neurol Sci. 2009;283(1-2):62-5.

22. Ravaglia G, Forti P, Maioli F, Sacchetti L, Mariani E, Nativio V, et al. Education, occupation, and prevalence of dementia: findings from the Conselice study. Dement Geriatr Cogn Disord. 2002;14(2):90-100.

23. Francesconi $\mathrm{P}$, Roti $\mathrm{L}$, Casotto V, Lauretani F, Lamponi M, Bandinelli S, et al. Prevalence of dementia in Tuscany: results from four population-based epidemiological studies. Epidemiol Prev. 2006;30(4-5):237-44.

24. Ferrucci L, Bandinelli S, Benvenuti E, Di lorio A, Macchi C, Harris TB, et al. Subsystems contributing to the decline in ability to walk: bridging the gap between epidemiology and geriatric practice in the InCHIANTI study. J Am Geriatr Soc. 2000:48(12):1618-25.

25. Di Bari M, Marchionni N, Ferrucci L, Pini R, Antonini E, Chiarlone M, et al. Heart failure in community-dwelling older persons: aims, design and adherence rate of the ICARe Dicomano project: an epidemiologic study. Insufficienza Cardiaca negli Anziani Residenti a Dicomano. J Am Geriatr Soc. 1999:47(6):664-71.

26. Hofman A, Rocca WA, Brayne C, Breteler MM, Clarke M, Cooper B, et al. The prevalence of dementia in Europe: a collaborative study of 1980-1990 findings. Eurodem Prevalence Research Group. Int J Epidemiol. 1991;20(3):736-48.

27. Lobo A, Launer LJ, Fratiglioni L, Andersen K, Di Carlo A, Breteler MM, et al. Prevalence of dementia and major subtypes in Europe: A collaborative study of population-based cohorts. Neurologic Diseases in the Elderly Research Group. Neurology. 2000;54(11 Suppl 5):S4-9.

28. Sorrentino GC, Caffari B, Vanacore N, Maggini M, Raschetti R. Le caratteristiche delle Unità di Valutazione Alzheimer (UVA) in relazione all'uso degli strumenti neuropsicologici. Ann Ist Super Sanita. 2005:41(1):63-8.

29. NHS, National Institute for Health Research, University of York, Centre for Reviews and Dissemination. Welcome to PROSPERO, International prospective register of systematic reviews. http://www.crd.york.ac.uk/PROSPERO/). Accessed 25 Mar 2016.

30. von Elm E, Altman DG, Egger M, Pocock SJ, Gøtzsche PC, Vandenbroucke JP, STROBE Initiative. The Strengthening the Reporting of Observational Studies in Epidemiology (STROBE) statement: guidelines for reporting observational studies. J Clin Epidemiol. 2008;61(4):344-9. 